\title{
Valuing Arts and Culture: A Research Agenda for Contingent Valuation
}

by Douglas S. Noonan

Assistant Professor

School of Public Policy

Georgia Institute of Technology

Douglas.Noonan@pubpolicy.gatech.edu

\section{Introduction}

This article introduces a burgeoning literature in cultural studies — contingent valuation of arts and culture_-and frames the research in a general policy setting. In 2002 alone, over 21 studies applying contingent valuation methodology (CVM) to value arts and cultural resources have been published. Assessing CVM in an arts policy context informs a research agenda for empirical, policy-relevant valuation research. Some limits and potential of applications of CVM to the arts can also be identified.

The economic value of arts productions and institutions is a matter of considerable and often heated debate. Measuring the economic value of particular arts policies is difficult at best, and sacrilege at worst. The hard case, when values are not captured readily by market prices, seems endemic to arts and cultural resources. A growing body of research has taken up the challenge to measure those values. The findings provide some useful insights about economic values, complementary to other values we might associate with the arts (Throsby 2001).

\section{Contingent Valuation}

There are several ways, in principle, to go about trying to estimate the economic value of artistic and cultural goods. One prominent technique is known as CVM. Thompson (1998) gives a good review of CVM in this journal. Essentially, CVM involves asking a sample of individuals how 
much they would be willing to pay for a change in the quantity of a good provided. This measurement approach comes from a well-developed literature among environmental economists, who frequently use CVM to estimate the value of environmental amenities and damages. ${ }^{1}$ Widespread application of the method in the field over the past several decades has led to the development of extensive guidelines for appropriate use of CVM. ${ }^{2}$

CVM studies take many forms. Typically, they involve conducting a sample survey to ask individuals their maximum willingness to pay (WTP) for some project or their minimum willingness to accept (WTA) as compensation for the loss of some resource. CVM surveys usually include detailed information about the current status and the hypothetical scenario under consideration. Respondents should be reminded of their budget constraints and available substitutes. CVM surveys often ask about motivations for WTP answers, in addition to the standard battery of demographic and other related information. Researchers can then estimate aggregate values across larger populations, identify socio-economic predictors of high and low values, and rank multiple projects and combinations of projects.

The variations on these basic elements of CVM surveys are as limitless as their applications. CVM surveys can be conducted over the telephone, by mail, or in-person. Some surveys use

\footnotetext{
${ }^{1}$ Of the 5,000 CVM studies produced thus far, most of them have studied environmental issues and less than $2 \%$ have addressed cultural resources.

${ }^{2}$ There are many guides to designing quality CVM surveys. Mitchell and Carson (1989) is one excellent resource. After CVM gained acceptance by the courts (in the State of Ohio v. Department of Interior, 1989) for natural resource damage assessment, concerted effort to develop guidelines for quality CVM surveys began. The National Oceanic and Atmospheric Administration (NOAA) assembled distinguished scholars into a panel, co-chaired by Nobel laureates Kenneth Arrow and Robert Solow, to evaluate the validity of CVM. The NOAA Report (Arrow et al 1993) endorsed CVM and published rigorous guidelines for quality studies. These guidelines have since been subjected to further scrutiny (Carson et al 1996, 2001). Numerous excellent guides exist for CVM practitioners and users today (e.g., Carson 2000, Whitehead 2000).
} 
elaborate maps and computer-generated photos to depict hypothetical scenarios. Values can be elicited in a wide variety of formats, including open-ended WTP questions that ask respondents to "fill in the blank" and referendum questions that ask respondents to vote "yes" or "no" on a proposal with a given price. Surveys can ask about multiple scenarios, either by eliciting multiple WTP responses from each individual or by splitting the sample and giving different scenarios to different sub-samples.

\section{Academic Critique}

Despite its promise, CVM is not without its critics - especially among economists. To some, survey data are inherently flawed measures of what people value. We can only learn this, they argue, by examining how individuals make real (not hypothetical) choices. If talk is cheap and only behavior can reveal preferences, this puts the valuation exercise in a real bind, because the types of artistic and cultural values of interest are precisely those that people can appreciate without doing anything. Although survey methods may be generally inferior, they are the only way to directly measure these non-use values of the arts. If we believe that the arts and culture have substantial non-use or external value, then CVM becomes “a regrettable necessity” in measurement (Epstein 2002).

Being the only measurement tool available for the task, critics like Diamond and Hausman argue, does not imply that "some number is better than no number” (1994). They point out numerous flaws in the method that make the results biased and unreliable. For instance, respondents may be answering a question different from the one asked. When the WTP for a single painting 
equals that for the entire gallery, this suggests respondents are confusing the part with the whole and biasing the results. ${ }^{3}$

Academics have produced a voluminous literature over the past several decades exploring the biases and reliability of CVM. A special issue of the Journal of Economic Perspectives captures well the tenor and content of the debate (Portney 1994, Hanemann 1994, Hausman and Diamond 1994). A more recent summary of the criticisms and defenses of CVM can be found in Carson et al. (2001). While consensus may still escape us, a wealth of knowledge about proper CVM survey design now exists.

Ultimately, it can be said that CVM is a tool that, with careful and limited application, can be used to provide important information about people's values for things that are overlooked by more conventional (i.e., market) means. CVM research is easy to do badly, costly to do well, and inevitably subject to a good deal of measurement "noise.” But, most of the serious criticisms of CVM can also be levied at standard market valuations as well. CVM performs quite well in the easy cases (private goods) and has more mixed success in the hard ones (esoteric values like pure existence value).

In some sense, this contentious track record is a necessary consequence of the lack of alternative benchmarks rather than inherent inadequacies of the method. CVM, like all measurement tools,

\footnotetext{
${ }^{3}$ Getting respondents to consider the same hypothetical construct is just one challenge. Respondents may face incentives to respond strategically, inflating or understating their true WTP. Different survey design features alleviate these concerns differently, with the referendum-style format commonly preferred. Other problems result from respondents biasing their answers to impress the interviewer or to save time and energy in answering the questionnaire. If preferences for the hypothetical good do not exist or are unlikely to be expressed reliably in the CVM survey, critics argue that CVM is no better than opinion polling, and good public policy should resort to expert panels (Diamond and Hausman 1994, Kahneman, Ritov, and Schkade 1999).
} 
is imperfect. But our alternatives are limited. Appealing to expert assessment does not solve this problem - because the issue is measuring the public's value, not the experts'. To paraphrase Hanemann (1994), how arts experts can estimate the public’s value of a particular exhibit without some form of survey of the public is unclear.

\section{Applications to Arts \& Culture}

Is a tool from the environmental arena appropriate for the cultural arena? There are many important similarities between environmental and cultural goods. Environmental amenities are often associated with recreational or "use” values, as well as many important "non-use” values. These values include existence value (e.g. people appreciate the Grand Canyon, even if they never intend to visit), altruistic value, option value, bequest value, or other intrinsic values. These non-use values are prominent in the cultural arena as well. CVM has been developed to measure these non-use values, and extending it to cultural goods and services appears to be a natural fit.

There are some special concerns when applying CVM in the arts and cultural arena. Navrud and Ready (2002) identify a number of challenges in applications to cultural heritage. These include defining the sampling frame, dealing with respondents unfamiliar with the good, and eliciting values for complex projects with positive and negative aspects.

Throsby (2002) argues that cultural goods pose problems to economic valuation for cultural goods for which individuals cannot imagine or express trade-offs. Artistic and cultural works with great significance for groups may not mean much to any individual members of that group. 
French citizens may recognize the great cultural value of the French language, accruing to all French people as a group, yet few would be willing to pay to preserve it as individuals. This sort of group-specific value may not be captured by individuals’ WTP.

A second limitation of CVM at the root of some cultural goods involves an inability of respondents to formulate preferences under the alternative scenario. Answering a WTP question typically involves a respondent comparing their well-being in two states of the world, the current and a hypothetical one. Respondents must know what they will want in both states. When individuals' expected benefits change or are unknown from one state to the next, CVM surveys may fail to provide reliable measures of value. Reliable surveys confine their topics to marginal changes only and avoid asking WTP questions about identities (e.g., WTP for being American, WTP for being in love).

While not applying CVM to areas where respondents cannot imagine their preferences under the hypothetical state seems straightforward enough, this admonition hints of a greater set of challenges. As McCain (1995) and Stigler and Becker (1977) argue persuasively, many arts and cultural goods are experiential; they involve a cultivation of taste. Consider the opera, where attending more arguably leads to greater appreciation and greater WTP. Asking for WTP to attend, then, might yield two different values depending on the perspective chosen. Looking ahead, the would-be attender has a smaller WTP for another performance than the same attender's retrospective value. Future CVM research - and valuation research in general - in arts and culture can benefit by confronting this cultivation of taste. 
Arts and cultural issues often evoke strong feelings both in favor and in opposition. When a population has both positive and negative values for something, care must be taken by the CVM researcher to measure this. Portney (1994) calls for more attention to be paid to this issue. As Epstein (2002) rightly points out, asking respondents for their WTP presupposes a lower bound of \$0, possibly prejudicing the survey instrument and disenfranchising many respondents. Rather than compensate for this ex post with statistical models (e.g, Santagata and Signorello 2000, Morey 2002), designing neutral surveys that accommodate positive and negative values would seem a more direct and efficient approach.

\section{Literature Review}

There have been numerous applications of CVM to arts-related goods, many of which have been reported in the academic literature. The first of these studies was conducted in the 1980s, but the great majority of cultural CVM studies have been published in the past decade. An annotated bibliography of the CVM literature on arts and culture (Noonan 2002) briefly summarizes each of the studies, their methods and their findings, and how they fit into the literature as a whole. As of January 2002, the bibliography contained 108 citations, and about half of those citations refer to arts resources (e.g., museums, theatre, performing arts). The number of citations has now grown to over 142. Nearly half of this body of research has been published since 2000 .

CVM applications to arts and cultural resources have typically fit into at least one of a few categories. These include: (1) admissions fee studies, undertaken at cultural institutions or heritage sites; (2) preservation studies, looking at WTP to maintain or restore certain cultural icons; (3) alternate funding studies, estimating WTP for a facility in lieu of the status quo 
funding; and (4) new project studies, estimating values for projects that affect or provide cultural resources. The first category represents the simplest use of CVM, applying the method to private (use) goods. The second category closely resembles common environmental CVM studies, where the cultural or built environment is the public good in question. The third category includes an eclectic mix of studies that normally ask for WTP to avoid losing some resource (e.g., access to a museum, an archive, arts generally). The quality of these studies ranges widely, as some hypothetical scenarios are better described than others. The fourth category includes studies tied directly to public policy by asking respondents to vote on policy proposals.

A closer look at the CVM studies of artistic resources reveals great variety in topics. A total of 33 original CVM studies of arts resources have been published, ranging in subject from Australian national arts funding to preserving Italy’s Galleria Civica. Table 1 provides summary information for selected CVM studies in the arts. They are organized chronologically within broad categories (arts, theatres, museums, broadcast). The table shows the year of the study, a brief description of the good being valued, the average WTP in 2002 US\$, and the survey sample size. Even a cursory glance at Table 1 reveals the variation in survey size, country of the study, scale of the good in question, and economic value obtained.

These CVM studies generally produce results that conform to our expectations. Survey design has predictable consequences for WTP responses. For instance, yes-no questions get higher WTPs than open-ended questions. Also, a social desirability bias may be evident in door-to-door interviews producing significantly higher values than phone interviews (by approximately \$40). ${ }^{4}$

\footnotetext{
${ }^{4}$ Obviously, causality flows both ways here. Survey administration modes are not chosen randomly. Minor projects or goods may not justify expensive door-to-door surveys. Few studies have employed multiple modes for
} 
In addition, an information bias may be present where informing respondents of their current tax liability for the arts tends to bias their WTP answers toward that amount. The bias is both in pushing the average WTP closer to the anchor-point given in the survey (Throsby and Withers 1986) and in narrowing the spread of answers around that anchor (Hansen 1997).

WTP results are also quite sensitive the characteristics of the artistic good in question. If the good is a vague "increase in government spending," respondents will tend to give higher values than for more specified goods. WTP values also appear to increase as the scope of the good increases. That said, higher values tend to be found for more geographically local goods. Moreover, the distribution of values for artistic goods is likely to have many zeros and a few very large values. These findings are typical of the CVM literature.

\section{A Political Economy of CVM}

CVM can provide evidence of the uncertain benefits to policymakers seeking to allocate scarce resources. Policymakers for major arts organizations and cultural institutions can benefit from better information about the public’s values. CVM can help improve pricing strategies, target fundraising efforts, and justify in-kind and other off-budget support (e.g., land grants, tax breaks, changes in intellectual property rights). Likewise, interest groups can use this information to better monitor politicians’ allocations of public resources, garnering preferential treatment as a result (Lohmann 1998). CVM’s influence will likely increase as reliable studies can be conducted at lower cost - a challenge for both practitioners and academics (Carson et al 2001).

the same "good," and none of those have used the same sample frame to compare in-person versus self-administered surveys. 
What sort of role will CVM play in arts policy? CVM is often met by arts organizations and agencies with a deep skepticism. It seems CVM has little to offer arts leaders who face no uncertainties or whose strategies and priorities do not depend on public values. Moreover, the proper marketplace for measuring the value of the arts may not be that of the popular marketplace but rather the political one. Arts agencies are embedded in political landscapes, full of constraints and actors with particular interests. Learning that preserving a theatre or charging admission at a museum could make society better off may simply fall on deaf ears if decisionmakers have something else in mind.

The utility of CVM comes in learning about what individuals value, and this is often secondary in arts policy. In some cases, arts experts and cultural elites decide what is worth pursuing. When arts policy is shielded from the preferences of the unwashed masses, CVM will have little to contribute. (Here, CVM researchers should be surveying only the policymakers.) CVM makes more sense when political leaders' fortunes are tied to their constituents' values. The democratic nature of CVM research clashes quite sharply with some elements of the arts policy world. Some resistance to CVM comes from a suspicion that ordinary people are poor judges of arts projects.

Others resist the entire notion of putting a price on the arts or culture. Some argue that economic valuation trivializes or demeans these "specially valued” things. Obviously, maintaining this “sacred” status can be a successful political strategy (especially if their economic value is relatively low). 
A general, positive political economic approach sheds light on CVM’s role in arts policy. Imagine a very simple world, where a single policymaker allocates resources to a variety of public services including the arts. Suppose he balances allocations among different public services to maximize net benefits for society (rather than himself). The optimum allocation occurs where the marginal net benefits of each project are equal. If we suppose that the benefits of each project are uncertain, things get more complicated. Investing in research (such as CVM) may reduce that uncertainty, but, unless he systematically underestimates the value of the arts, we should expect the CVM research to inspire reductions in arts funding as much as increases. ${ }^{5}$ Arts advocates commissioning CVM research can expect gains for arts funding if they believe the policymaker underestimates arts values. Thus, confidence that the policymaker correctly estimates projects’ value, at least on average, may explain some disinterest in using CVM. A strong aversion to the possibility of unfavorable findings can also explain CVM disinterest even among those advocates who believe policymakers underestimate arts projects’ benefits.

Bennedsen and Feldmann (2002) go on to show, however, how this situation can change dramatically when policies are taken by legislatures rather than dictators. Lobbyists can provide information about how different constituents value a project, thereby allowing legislators to form coalitions around those projects. For instance, a citywide performing arts organization might undertake CVM studies across neighborhoods to measure local benefits, which could then be used to identify a coalition of city council representatives whose constituents would benefit from increased funding. This helps the legislators as well as the lobbyists who get their project

\footnotetext{
${ }^{5}$ Here, we assume a risk-neutral policymaker. If he is averse to riskier ventures, CVM may-in expectation—lead to increases in allocations to arts funding by lowering the uncertainty associated with its net benefits. Policymakers investment in uncertainty-reducing research is thus influenced by their relative risk-aversion and the cost of research.
} 
undertaken. Bennedsen and Feldmann suggest that this coalition-forming role of information helps explain why parliamentary legislatures in Europe receive less information lobbying than the majoritarian counterparts in the U.S. It is interesting to note that, although more CVM studies in arts and culture have been undertaken in countries with parliamentary systems, the proportion of studies concerning government arts funding decisions is greater in the U.S.. ${ }^{6}$ Moreover, non-governmental funding has supported a greater proportion of CVM research in the U.S. than elsewhere. ${ }^{7}$

Up to this point, the double-edged sword of better information about public goods values may be sufficient to deter expensive research that might yield answers unfavorable to arts constituents or patrons. This relegates CVM's future primarily to informing managers at cultural institutions and helping broad-based arts lobbies identify coalitions. And, if policymakers' expectations of arts’ value start deviating from arts organizations’ expectations, then CVM can give evidence to correct this. CVM may also be called upon to justify projects as part of cost-benefit analyses, which themselves are subject to political influences (Posner 2002). Further research into the role of information lobbying on policy will shed light on the ways we can expect CVM to be used.

\section{Communicating CVM}

Effectively communicating CVM findings poses another challenge to practitioners. Few people understand CVM. Researchers should convey how CVM works and its limits. Communicating

\footnotetext{
${ }^{6}$ Two of the fourteen published CVM studies of arts and cultural resources in the U.S. consider government spending levels as the "good" in question, compared with four out of fifty studies outside of the U.S..

${ }^{7}$ Of the thirty-two published CVM studies of arts and cultural resources listing their funding sources, 59\% were funded by governments, $16 \%$ by nonprofit organizations, and $9 \%$ by both. (The remainder were funded by universities or the World Bank.) These proportions change to 30\%, 30\%, and 10\% for the ten American studies.
} 
CVM findings requires emphasizing at least a few major points. (1) Fully describe the precise nature of the good or project that was valued. Reliable CVM studies elicit values for narrowly defined constructs, and care must be taken to reflect this specificity in reporting results. (2) Describe the distribution of WTP values, rather than just point estimates of average WTP. One advantage of CVM is its ability to describe the distribution of WTP. Reporting confidence intervals, means, medians, and information about the tails of the distribution lends credibility as well as more information. (3) Distinguish CVM results from opinion polling by emphasizing that these values reflect trade-offs that respondents made. The values that result from (simulated) trade-offs should carry a weight lacking in opinion polls, where talk is cheap(er). (4) Clearly portray the socio-economic determinants of WTP responses. Linking WTP values with individuals’ characteristics adds another dimension to CVM findings, especially for audiences who are interested in distributional issues.

Past research has shown us the many limitations of CVM. Careful survey design can leverage these limitations to help communicate the results. Conservative design (anonymity, WTP not WTA, emphasis on substitutes and budgets) and estimation techniques should be used. It is often more effective to show that the true WTP is at least as large as reported than to produce an estimate with ambiguous bias. Extensive pretesting can spot potential pitfalls and control for them before the final results.

Finally, alternative metrics can be used in reporting the results. Some audiences may reject or discount findings that measure artistic and cultural values in dollar terms. An alternative numeraire can often be found from within the survey (e.g., the museum's conservation fund 
would be as valuable as 1.5 new exhibits) and from outside (e.g., Canadians are willing to pay half as much in taxes to support arts as their tax contributions for housing). Expressing CVM values in non-monetary terms should broaden CVM's appeal as well as better contextualize the findings.

\section{Promising Research Areas}

There are many areas in the arts and culture arena that appear ripe for application of CVM. These range from the more "traditional” marketing-oriented applications to valuation studies of spillovers from the arts and cultural resources. Table 2 summarizes some of them.

Simple use-value studies, the most popular CVM research in the arts arena, hold considerable promise for managers of cultural institutions. Studies of WTP for entrance to a museum, gallery, or exhibit can inform better design of admission fees. Even for facilities that cannot or do not charge for admission, these studies can provide estimates of the public's total use value, often useful in justifying increased funding. More innovative research can push the envelope further and measure values for characteristics or sub-components of exhibits, recreational sites, and even programmatic content. WTP for memberships, season tickets, or subscriptions should vary along with the services and content. For example, theatres could use CVM to predict changes in subscription and attendance attributable to different mixes of productions in a season. Similarly, museum directors can evaluate potential revenue streams from ancillary services, special exhibits, and other activities. There is still much to learn about the demand for arts and cultural experiences. 
CVM's comparative advantage as a research tool lies in its ability to quantify the impact and value of public, “external effects” of the arts. It has long been argued that museum visitation, arts education, and other cultural experiences have substantial indirect benefits. It has been claimed that museums “civilize” visitors, conferring important shared cultural knowledge (Smolensky 1986). Likewise, it is widely held that children exposed to arts curriculum become better members of society. For instance, a recent survey in California found widespread belief in the arts' and arts education’s external benefits. Some tools to measure those benefits, like economic impact studies, have not been up to the task (Seaman 1987). While direct evidence of arts education's impact on external outcomes may be lacking (Winner and Hetland 2001), this does not mean that people do not value arts for their external effects. Widespread belief in the arts improving children’s academic performance (e.g., California Arts Council 2001) suggests that values may be quite large, regardless of observable effects on outcomes.

CVM can reveal the nature and extent of these external benefits by carefully asking the right questions: what would you be willing to pay to increase the number school class trips to Museum X? Does that WTP vary depending on the content of the museum, the students' characteristics, or the frequency of visits? CVM surveys can get information about the value of arts education for parents and for the general public. Here, research can inform how parents (and the public) would trade-off between arts curriculum and other subjects. Valuation research can even indicate how much of people's value for the arts derives from its cultural education role as opposed to its more instrumental role (e.g., increasing test scores). The same holds in museums. Even though most CVM applications in museums only examine WTP for admission, one’s own use of a facility is just one, possibly small, part of its overall value. Individuals may value 
others' ability to visit, others' actual visits, future use, and the mere existence of the museum. Gate receipts and enrollment in arts classes don't capture these values. Additional research is needed to rigorously investigate the external (non-use) benefits of arts and cultural resources. ${ }^{8}$

CVM research can be fruitfully applied to other public arts enterprises, such as arts districts and public art projects. City managers looking to revitalize downtown areas frequently turn to organizing agglomerations of theatres, galleries, and other artistic facilities. The composition of these urban arts and heritage districts involves balancing arts organizations’ interests, public demand, and infrastructural constraints. Contingent valuation methods can guide policymakers facing these trade-offs, from grand decisions over which arts should be represented to pragmatic issues of how many trees to plant. Urban planners recognize an important role for arts and culture in tomorrow's cities, yet surprisingly little is known about the mix, presentation, and quantity of arts that residents will want. CVM research can shed some light onto how people value a vibrant arts scene and what that entails. Moreover, some lessons can be learned without the costly trial-and-error of constructing an arts district in the dark. Public art offers another example where much can be learned without first undertaking expensive (and often irreversible) projects. CVM surveys can elicit feedback about alternative public art projects, suggesting which features will and will not be popular. Incorporating detailed graphics to help respondents visualize the proposal and a host of variants is limited only by the designer's imagination and the respondents' time.

\footnotetext{
${ }^{8}$ An interesting line of future research would be to compare these values with evidence on actual outcomes. Consider Chicago's popular Gallery 37, youth program that combines generic job training with arts education. In principle, the program's effects on outcomes are measurable and comparable to other job training programs'. The relationship between public WTP for Gallery 37 and its demonstrated effects, if any, would begin to illuminate our understanding of the value of arts exposure and its relationship to observable outcomes.
} 
CVM can improve our understanding of other non-market arts and cultural resources. For example, libraries and archives engage two non-use values: option value and preservation value. Their missions to warehouse cultural resources for future use are unlikely to be supported by the market. Learning more about how society values library and archive services can at least guide our priorities and perhaps lead to creative financing mechanisms. Future research might compare library and archives to preserving species and natural resources for future generations. Preserving arts and culture that require active performance or practice warrants additional valuation research. Although the costs of maintaining certain traditions (e.g., traditional crafts, languages, performance of Wagner's Ring cycle opera) may be readily measurable, their benefits to the public at large are less well understood. How do we value preserving and bequeathing those things that cannot be placed neatly on a library's shelf?

In a similar vein, gauging the public's interest in certain artistic and cultural resources has important policy implications for intellectual property and copyright laws. Difficult policy choices may arise when considering shifting some resources into or out of the public realm. Numerous cultural and artistic works of great social importance rest in private hands, and legislation such as the Visual Arts Rights Act has sought to protect the public's interest. Regardless of how to best protect the public's interest in a particular work of art, the question of measuring those interests remains open and, in principle, answerable by CVM. The costs (and benefits) of “Disney-fication” of cultural resources are empirical issues. CVM can provide important insights in the struggle to balance commercial and artistic interests. 
A final area of application for CVM in arts and culture addresses the abstract notion of group identity. Some manifestations of cultural identity seem to be universally, although rarely uniformly, popular among area residents. Inclusive town fairs and festivals, for example, may perpetuate important traditions and confer a sense of place to residents and participants. Other symbols engender intense controversy (e.g., museum exhibits, the Confederate flag, certain parades). Planning for and justifying arts and cultural events can benefit from measuring how users and non-users value them. These resources present dual challenges for CVM research to separate the symbolic values from the project at hand and to neutrally account for possibly diametrically opposed values. Research in these areas risks pushing CVM beyond its limits (Throsby 2001, 2002) by eliciting WTP for identity rather than a good or a project. Future theoretical work may do well to take up where Throsby left off and examine how cultural identity shapes (economic) values and vice versa, and how this might affect survey responses empirically.

Research in these areas would provide new evidence about the public's values in arts and culture. It would also push the tools of CVM further into uncharted territory. How far do Throsby’s reservations extend? How does accounting for the cultivation of taste affect the policy implications of CVM findings?

\section{Conclusion}

As the arts and cultural sector grows, new techniques for demonstrating the arts' worth to policymakers will become more valuable. Evidence for this can be founding in the rapidly growing number of applications of economic valuation techniques to artistic and cultural 
resources. Academics, regional and local governments, and non-governmental agencies have conducted CVM studies to measure the value of artistic resources. These studies reveal important information about the nature of demand for the arts. They also arm arts advocates with quantifiable evidence in support of their project's value to society. Although not promising a perfect measure of value, CVM has much to offer in the arts and culture arena. Future CVM research is well-positioned to provide important information for applied as well as theoretical research in arts and culture.

\section{References}

Arrow, Kenneth, Robert Solow, Paul Portney, Edward Leamer, Roy Radner, and Howard Schuman. 1993. "Report of the National Oceanic and Atmospheric Administration Panel on Contingent Valuation.” Federal Register 58(10): 4601-4614.

Barros, Carlos. 1998."Willingness to Pay for Public Museums: Hypothetical and Real Commitments.” Paper presented at the Tenth International Conference on Cultural Economics, Barcelona, 14-17 June 1998.

Bégin, Dominique, François Colbert, and Ruth Dupré. 2000. “Comparative Analysis of French and French-Canadian Willingness to Support the National Film Industry.” International Journal of Cultural Policy 7(2): 355-368.

Bennedsen, Morten and Sven E. Feldmann. 2002. “Lobbying Legislatures.” Journal of Political Economy 110(4): 919-946.

Boxall, Peter C., Jeffrey Englin, and Wiktor L. Adamowicz. 2002. “The Contribution of Aboriginal Rock Paintings to Wilderness Recreation Values in North America.” In Ståle Navrud and Richard C. Ready, eds. Valuing Cultural Heritage: Applying Environmental Valuation Techniques to Historic Buildings, Monuments and Artifacts (Northampton, MA: Edward Elgar Publishing).

Bravi, Marina, Riccardo Scarpa, and Gemma Sirchia. 2002. "Valuing Cultural Services in Italian Museums: A Contingent Valuation Study.” In Ståle Navrud and Richard C. Ready, eds. Valuing Cultural Heritage: Applying Environmental Valuation Techniques to Historic Buildings, Monuments and Artifacts (Northampton, MA: Edward Elgar Publishing). 
California Arts Council. 2001. Public Opinion Survey 2001. http://www.cac.ca.gov/library/publications/publication_files/Public_Opinion_Survey.pdf (last accessed: 23 August 2002).

Carson, Richard T. 2000. “Contingent Valuation: A User’s Guide,” Environmental Science and Technology 34: 1413-1418.

Carson, Richard T. W. Michael Hanemann, Raymond J. Kopp, Jon A. Krosnick, Robert C. Mitchell, Stanley Presser, Paul A. Rudd, V. Kerry Smith. 1996. "Was the NOAA Panel Correct about Contingent Valuation?” Discussion paper 96-20, Resources for the Future.

Carson, Richard T., Nicholas E. Flores, and Norman F. Meade. 2001. "Contingent Valuation: Controversies and Evidence.” Environmental and Resource Economics 19: 173-210.

Causi, Marco, Massimiliano Mazzanti, and Anna Montini. 2002. “A Survey Study on Visitors of the Frescos' Restoration Yard at S. Francis Cathedral in Assisi. An Analysis of Individual WTP and Visitor's Preferences.” Paper presented at the 12th Biennial ACEI Conference, Rotterdam, 13-15 June 2002.

Decision Research. 2001. “The Arts in Orange County: A Public Opinion Survey Report,” Executive Summary of Orange County Arts Public Opinion Survey. http://www.artsoc.org/what_we_do/public_opinion_survey.pdf (last accessed: 23 August 2002).

Delaney, Liam. 2002. "Irish National Broadcasting: Assessing the Benefits with the Contingent Valuation Method.” Paper presented at the 12th Biennial ACEI Conference, Rotterdam, 13-15 June 2002.

Diamond, Peter A. and Jerry A. Hausman. 1994. “Contingent Valuation: Is Some Number Better than No Number?” Journal of Economic Perspectives 8(4): 45-64.

Economics for the Environmental Consultancy (EFTEC). 2000. Valuing Our Recorded Heritage, Final Report. Report to the Museums and Galleries Commission, London.

Epstein, Richard A. 2002. “The Regrettable Necessity of Contingent Valuation” Paper presented to "The Contingent Valuation of Culture" conference, Cultural Policy Center at the University of Chicago, Chicago, 1-2 February 2002.

Fleischer, Aliza and Daniel Felsenstein. 2002. "Cost-Benefit Analysis Using Economic Surpluses: A Case Study of a Televised Event.” Journal of Cultural Economics 26(2): 139-156.

Getzner, Michael and Caroline Oberlercher. 2002. "Contributions to Cultural Economics: the Case of Austria.” Discussion Paper of the College of Business Administration, University of Klagenfurt, Austria. February 2002. 
Glass, Robert H., et. al. 1999. "Economic Scope, Impact and Marketing Study of the Kansas Arts Commission.” The University of Kansas, Institute for Public Policy and Business Research Report No. 257, July 28.

Gregory, Robin. 1986. “Interpreting Measures of Economic Loss: Evidence from Contingent Valuation and Experimental Studies.” Journal of Environmental Economics and Management 13: 325-337.

Hanemann, W. Michael. 1994. "Valuing the Environment through Contingent Valuation.” Journal of Economic Perspectives 8(4): 19-43.

Hansen, Trine Bille. 1997. "The Willingness-to-Pay for the Royal Theatre in Copenhagen as a Public Good.” Journal of Cultural Economics 21(1): 1-28.

Kahneman, Daniel, Ilana Ritov, and David Schkade. 1999. "Economic preferences or attitude expressions? An analysis of dollar responses to public issues.” Journal of Risk and Uncertainty 19: 220-242.

Lara, José Ángel Sanz, Luis César Herrero Prieto, and Ana María Bedate Centeno. 2002. "Contingent Valuation and Semiparametric Methods. Application to the National Museum of Sculpture of Valladolid (Spain).” Paper presented at the 12th Biennial ACEI Conference, Rotterdam, 13-15 June 2002.

Lohmann, Susanne. 1998. “An Information Rationale for the Power of Special Interests.” American Political Science Review 92: 809-27.

Maddison, David and Terry Foster. 2002. "Valuing Congestion Costs in the British Museum.” Paper presented to "The Contingent Valuation of Culture” conference, Cultural Policy Center at the University of Chicago, Chicago, 1-2 February 2002.

Martin, Fernand. 1994. “Determining the Size of Museum Subsidies.” Journal of Cultural Economics 18(4): 255-270.

Mazzanti, Massimiliamo. 2002. "Valuing Cultural Heritage Services by Choice Modeling Experiments: Visitor Study at the Galleria Borghese in Rome.” Paper presented at the 12th Biennial ACEI Conference, Rotterdam, 13-15 June 2002.

McCain, Roger A. 1995. "Cultivation of Taste and Bounded Rationality: Some Computer Simulations.” Journal of Cultural Economics 19(1): 1-15.

Mitchell, Robert C. and Richard T. Carson. 1989. Using Surveys to Value Public Goods: The Contingent Valuation Method (Washington, DC: Resources for the Future).

Morey, Edward and Kathleen Greer Rossmann. 2002. “Using Stated-Preference Questions to Investigate Variation in Willingness to Pay for Preserving Marble Monuments: Classical Heterogeneity and Random Parameters." Paper presented to "The Contingent Valuation 
of Culture” conference, Cultural Policy Center at the University of Chicago, Chicago, 1-2 February 2002.

Morrison, William G. and E. G. West. 1986. "Subsidies for the Performing Arts: Evidence on Voter Preference.” Journal of Behavioral Economics 15: 57-72.

Navrud, Ståle and Richard C. Ready. 2002. Valuing Cultural Heritage: Applying Environmental Valuation Techniques to Historic Buildings, Monuments and Artifacts. (Northampton, MA: Edward Elgar Publishing).

Noonan, Douglas S. 2002. "Contingent Valuation Studies in the Arts and Culture: An Annotated Bibliography.” University of Chicago Cultural Policy Center working paper 11.

Papandrea, Franco. 1999. “Willingness to Pay for Domestic Television Programming.” Journal of Cultural Economics 23(3): 147-164.

Portney, Paul R. 1994. "The Contingent Valuation Debate: Why Economists Should Care.” Journal of Economic Perspectives 8(4): 3-17.

Posner, Eric A. “Controlling Agencies With Cost-Benefit Analysis: A Positive Political Theory Perspective.” University of Chicago Law Review 68(4): 1137-1199.

Roche Rivera, Hugo.1998. “The Willingness-to-Pay for a Public Mixed Good: the COLON Theatre in Argentina,” Presented at the Tenth International Conference on Cultural Economics, Barcelona, 14-17 June 1998.

Santagata, Walter and Giovanni Signorello. 2000. “Contingent Valuation of a Cultural Public Good and Policy Design: The Case of "Napoli Musei Aperti"” Journal of Cultural Economics 24(3): 181-204.

Schwer, R. Keith and Rennae Daneshvary. 1999. "The Impact of Casino Gambling on Charitable Contributions: The Willingness to Contribute to a Local Public Television Station.” Review of Regional Studies 29(1): 77-89.

Seaman, Bruce A. 1987. “Arts Impact Studies: A Fashionable Excess.” In Anthony J. Radlich, ed. Economic Impact of the Arts: A Sourcebook (Denver, CO: National Conference of State Legislatures).

Smolensky, Eugene. 1986. “Municipal Financing of U.S. Fine Arts Museums: A Historical Rationale.” Journal of Economic History 46(3): 757-768.

Snowball, J. D. and G. G. Antrobus. 2001. "Measuring the Value of the Arts to Society: The Importance of the Value of Externalities for Lower Income and Education Groups in South Africa.” South African Journal of Economics 69(4): 752-766. 
Stigler, George J. and Gary S. Becker. 1977. “De Gustibus Non Est Disputandum.” American Economic Review 67(2): 76-90.

Thompson, B. J., C. David Throsby, and Glenn A. Withers. 1983. "Measuring Community Benefits from the Arts.” Research Paper No. 261 (School of Economic and Financial Studies, Macquarie University).

Thompson, Eric C. 1998. “Contingent Valuation in Arts Impact Studies.” Journal of Arts Management, Law, and Society. 28(3): 206-210.

Thompson, Eric, Mark Berger, Glenn Blomquist, and Steve Allen. 2002. "Valuing the Arts: A Contingent Valuation Approach.” Journal of Cultural Economics 26(2): 87-113.

Throsby, C. David. 2001. Economics and Culture. (Cambridge UK: Cambridge University Press).

Throsby, C. David. 2002. "Determining the value of cultural goods: How much (or how little) does contingent valuation tell us?” Paper presented to “The Contingent Valuation of Culture” conference, Cultural Policy Center at the University of Chicago, Chicago, 1-2 February 2002.

Throsby, C. David and Margaret O’Shea. 1980 . “The Regional Economic Impact of the Mildura Arts Centre.” Research Paper No. 210 (School of Economic and Financial Studies, Macquarie University).

Throsby, C. David, Glenn A. Withers. 1986. "Strategic Bias and Demand for Public Good: Theory and an Application to the Arts.” Journal of Public Economics 31(3): 307-321.

Whitehead, John C. 2000. “A Practitioner's Primer on Contingent Valuation.” Department of Economics Working Paper, East Carolina University, April 2000.

Winner, Ellen and Lois Hetland. 2000. "The Arts in Education: Evaluating the Evidence for a Causal Link.” Journal of Aesthetic Education 34(3-4): 3-10. 
Table 1: WTP for Selected Studies

\begin{tabular}{|c|c|c|c|c|c|}
\hline Authors & $\begin{array}{l}\text { Year of } \\
\text { study }\end{array}$ & Category & Good(s) & $\begin{array}{l}\text { Average } \\
\text { WTP }\end{array}$ & $\begin{array}{l}\text { Sample } \\
\text { size }\end{array}$ \\
\hline Throsby and O’Shea (1980) & 1979 & Arts & increasing activities of Arts Centre in Mildura through taxes & $18.36 *$ & 60 \\
\hline Thompson, et al (1983) & 1982 & Arts & supporting Australian arts at current level through taxes & 38.45 & 827 \\
\hline Morrison and West (1986) & 1984 & Arts & supporting for performing arts in Ontario through taxes & 9.67 & 463 \\
\hline Thompson, et al (2002) & 1997 & Arts & preventing losing $25 \%$ of arts in Kentucky through donations & $12.69 *$ & 168 \\
\hline Glass, et al (1999) & 1999 & Arts & substantially increasing in local area arts in Kansas via taxes & $20.52 *$ & 515 \\
\hline Snowball and Antrobus (2001) & 2000 & Arts & holding arts festival in Grahamstown through taxes & 8.90 & 66 \\
\hline Decision Research (2001) & 2001 & Arts & supporting arts in Orange County, CA through taxes & 4.03 & 500 \\
\hline California Arts Council (2001) & 2001 & Arts & funding arts in California through taxes & 5.01 & 1200 \\
\hline Hansen (1997) & 1993 & Theatres & supporting the Royal Theatre in Copenhagen through taxes & 12.94 & 925 \\
\hline Roche Rivera (1998) & 1998 & Theatres & rehabilitating the Teatro Colon & 63.80* & 3036 \\
\hline Gregory (1986) & 1986 & Museums & viewing BC Provincial Museum exhibits & $11.87^{\circ}$ & 63 \\
\hline Martin (1994) & 1992 & Museums & supporting all Quebec museums through taxes & $8.62 *$ & 908 \\
\hline Boxall, et al (2002) & 1995 & Museums & visiting aboriginal rock painting in Canadian park & $145.10^{\circ *}$ & 431 \\
\hline Bravi, et al (2002) & 1996 & Museums & preventing service decline at Rivoli Castle & $25.36^{\circ}$ & 1323 \\
\hline Barros (1998) & 1996 & Museums & preserving heritage at Lisbon's Chiado Museum through taxes & $13.49 *$ & 253 \\
\hline Maddison and Foster (2002) & 2000 & Museums & congestion costs in the British Museum, per marginal visitor & $12.40^{\circ *}$ & 400 \\
\hline Mazzanti (2002) & 2000 & Museums & $\begin{array}{l}\text { conservation activities in the Galleria Borghese in Rome } \\
\text { through admission fees }\end{array}$ & $3.79^{\circ}$ & 185 \\
\hline Getzner and Oberlercher (2002) & 2000 & Museums & admission to folklore museum in Austria & $7.57^{\circ *}$ & 107 \\
\hline EFTEC (2000) & 2000 & Museums & prevent deterioration of U.K. picture library & $22.68 *$ & 35 \\
\hline Causi, et al (2002) & 2001 & Museums & $\begin{array}{l}\text { keeping open frescos in St. Francis Cathedral in Assisi through } \\
\text { donation }\end{array}$ & $4.67^{\circ}$ & 400 \\
\hline Lara, et al (2002) & 2001 & Museums & preserving National Museum of Sculpture, Spain through taxes & $24.11^{*}$ & 1014 \\
\hline Schwer and Daneshvary (1995) & 1993 & Broadcast & keeping PBS TV in Las Vegas through donations & $31.01 *$ & 229 \\
\hline Papandrea (1999) & 1994 & Broadcast & increase domestic TV programming by $10 \%$ & 10.82 & 2193 \\
\hline Bégin and Colbert (2000) & 1998 & Broadcast & supporting Quebec commercial filmmaking industry via taxes & $19.57 *$ & 123 \\
\hline Fleischer and Felsenstein (2002) & 1999 & Broadcast & having Israel host the Eurovision Song Contest & $2.55^{\circ *}$ & 500 \\
\hline Delaney (2002) & 2002 & Broadcast & preserving Irish public broadcaster through taxes & 136.76 & 360 \\
\hline
\end{tabular}


Table 2: Examples of Future Areas of CVM Research in Arts and Culture

\begin{tabular}{|c|c|l|}
\hline \multicolumn{1}{|c|}{ Topic or Good } & Type of Value & \multicolumn{1}{|c|}{ Audience } \\
\hline $\begin{array}{c}\text { Cultural site visitation } \\
\text { (exhibit content, program content, } \\
\text { ancillary services, congestion) }\end{array}$ & Use value & Managers of cultural institutions \\
\hline $\begin{array}{c}\text { Arts education } \\
\text { (quantity, content, settings) }\end{array}$ & Non-use value & $\begin{array}{l}\text { Arts councils, schools, urban } \\
\text { developers }\end{array}$ \\
\hline $\begin{array}{c}\text { Arts exposure } \\
\text { (visitation, access, blockbusters) }\end{array}$ & Non-use value & $\begin{array}{l}\text { Managers of cultural institutions, } \\
\text { arts councils, foundations }\end{array}$ \\
\hline $\begin{array}{c}\text { Archives and arts preservation } \\
\text { (public and private) }\end{array}$ & Non-use value & $\begin{array}{l}\text { Librarians, museums, courts, } \\
\text { legislators }\end{array}$ \\
\hline Arts districts and public art & $\begin{array}{c}\text { Use and non-use } \\
\text { value }\end{array}$ & City planners and developers \\
\hline $\begin{array}{c}\text { Cultural identity } \\
\text { (fairs, exhibits, parades) }\end{array}$ & $\begin{array}{c}\text { Use and non-use } \\
\text { value }\end{array}$ & City managers, arts councils \\
\hline
\end{tabular}

